\title{
Investigation of the Interaction of Sodium Chloride and Two Amino Sulfonic Acids, HEPES and MOPSO, by EMF Measurements
}

Y. C. Wu, Daming Feng, and W. F. Koch

National Institute of Standards and Technology, Gaithersburg, MD 20899
Ionic interactions in the two systems $\mathrm{NaCl}-\mathrm{HEPES}$ (N-2-hydroxyethylpiperazine-N'-2-ethanesulfonic acid ) and

$\mathrm{NaCl}-\mathrm{MOPSO}$ (3-(N-Morpholino)-2hydroxypropanesulfonic acid) have been studied in terms of their mutual influence on the respective activity coefficients of each component. Activity coefficients for each component of the two systems and for corresponding buffers are calculated from emf measurements of solutions containing $\mathrm{NaCl}$, the aminosulfonic acid, and its conjugate base in a NaISE/solution/

$\mathrm{AgCl}-\mathrm{Ag}$ cell at 5, 15, 25, and $37^{\circ} \mathrm{C}$.

Key words: activity coefficient; amino acid; emf; HEPES; MOPSO; salt interaction; sodium chloride.

Accepted: August 20, 1991

\section{Introduction}

The interaction between an amino acid and a neutral salt in solution can be described in terms of the activity coefficients of the components [1]. In this laboratory, when we decided to establish HEPES(N-2-hydroxyethylpiperazine-N'-2-ethanesulfonic acid) as a pH Standard Reference Material (SRM) for physiological application, we needed to know the effect of HEPES on the activity coefficient of $\mathrm{NaCl}$. Since there were no relevant data in the literature, we had to assume that the influence of HEPES on the activity coefficient of $\mathrm{NaCl}$ was the same as that of glycine on $\mathrm{NaCl}$ [2]. Even though the effect was small, it was necessary to verify our assumption. MOPSO(3[N-Morpholino]-2-hydroxypropanesulfonic acid) is another candidate for an SRM in the physiological $\mathrm{pH}$ range. The influence of MOPSO on the activity coefficient of $\mathrm{NaCl}$ is also not known. The purposes of this investigation were to determine the mutual influence between $\mathrm{NaCl}$ and HEPES, and between $\mathrm{NaCl}$ and MOPSO, and to provide the data needed to calculate the activity coefficients for $\mathrm{NaCl}, \mathrm{HEPES}$, and MOPSO in the respective mixed solutions. The determination of the activity coefficient of amino acids and $\mathrm{NaCl}$ in their mixed solutions may be done by potentiometry. One approach using a sodium amalgam electrode has been reported [3]. However, it was found that the amino acids decomposed sodium amalgam and evolution of hydrogen gas was observed. For this reason, the sodium ion-selective electrode (NaISE) provided a more convenient approach to this type of determination.

\section{Experimental}

\subsection{The Apparatus}

The cells studied were of the type

$$
\mathrm{NaISE} / \mathrm{NaCl}\left(m_{1}\right) / \mathrm{AgCl}-\mathrm{Ag}
$$

for the pure $\mathrm{NaCl}$ solution, and 


$$
\begin{aligned}
& \mathrm{NaISE} / \mathrm{NaCl}\left(m_{1}\right), \operatorname{HEPES}\left(m_{2}\right), \\
& \text { NaHEPESate }\left(m_{3}\right) / \mathrm{AgCl}-\mathrm{Ag} \\
& \mathrm{NaISE} / \mathrm{NaCl}\left(m_{1}\right), \operatorname{MOPSO}\left(m_{2}\right), \\
& \text { NaMOPSOate }\left(m_{3}\right) / \mathrm{AgCl}-\mathrm{Ag}
\end{aligned}
$$

for the two-component systems $\left(m_{3}=0\right)$ and threecomponent systems for HEPES (II) and MOPSO (III). A glass NaISE (13-620-500, Fisher Scientific $^{1}$ was used for the measurements for solutions containing HEPES. However, in solutions containing MOPSO the emf readings drifted continually and were not reproducible. It appeared that the MOPSO coated the glass surface of the electrode. Thus, it was necessary to use a PVC membrane neutral carrier-based NaISE (provided by Prof. W. Simon, Zürich, Switzerland [4]) for the MOPSO system. The silver-silver chloride reference electrodes were identical with those used previously in this laboratory [2]. emfs were measured using an Orion 701A pH meter with a sensitivity of $0.1 \mathrm{mV}$. Measurements were made at various temperatures in a bath controlled to $\pm 0.01^{\circ} \mathrm{C}$ [2]. The electrodes were calibrated daily using $\mathrm{NaCl}$ solutions in cell (I). Activity coefficients of $\mathrm{NaCl}$ were taken from the literature [5]. The observed (Nernstian) slopes $k$ for both glass and PVC membrane NaISEs were constant for each calibration with a standard deviation of $0.05 \mathrm{mV}$ for the whole range of temperatures in this study. The values are shown in Tables 1 and 2. They were about $1 \mathrm{mV}$ lower than the theoretical Nernstian slopes; hence, the electrodes were not thermodynamically reversible, but were still useful for the purpose of this study. The selectivity of the two NaISEs toward the hydrogen ion requires that the $\mathrm{pH}$ of the solutions should be between 4.5 and 10 at the $\mathrm{NaCl}$ concentration of 0.01-0.1 $m[4,6]$. In this study, the $\mathrm{pH}$ of the solutions was 5.5-7.5, which was well within the range of requirement.

\subsection{Materials}

$\mathrm{NaCl}$ was ACS reagent grade and was dried at $110^{\circ} \mathrm{C}$ for $4 \mathrm{~h}$ before use. HEPES and MOPSO (Sigma Co., St. Louis, MO) were recrystallized from $80 \%$ and $70 \%$ ethanol/water solutions respectively, and were dried in a vacuum oven at $50^{\circ} \mathrm{C}$

\footnotetext{
${ }^{1}$ Certain commercial equipment, instruments, or materials are identified in this report to specify adequately the experimental procedure. Such identification does not imply recommendation or endorsement by the National Institute of Standards and Technology, nor does it imply that the materials or equipment identified are necessarily the best available for the purpose.
}

overnight. Their sodium salt solutions were made by neutralizing the acid solutions with standard sodium hydroxide. Stock solutions were prepared by weight. All mass measurements were made with an accuracy to 0.03 mass percent and air buoyancy corrections were applied for all masses used. The laboratory distilled water used in this experiment was passed through a deionizing column and had a conductivity of less than $1 \mu \mathrm{S} / \mathrm{cm}$.

\section{Results}

The emfs of cells (II) and (III) can be empirically expressed as an equation similar to the Nernstian equation:

$$
E=E_{0}-k \log \left(m_{\mathrm{Na}} m_{\mathrm{Cl}}{\gamma_{\mathrm{t}}}^{2}\right)
$$

where $\gamma_{1}$ is the mean molal activity coefficient of $\mathrm{NaCl}$ and $m$ is the molal concentration, $E_{0}$ is an extrapolated constant, and $k$ (in $\mathrm{mV}$ ) is another constant.

For pure $\mathrm{NaCl}$ solutions in cell (I), the emf is expressed as

$$
E_{\mathrm{p}}=E_{0}-2 k \log \left(m_{1} \gamma_{1}{ }^{\circ}\right)
$$

where $\gamma_{1}{ }^{\circ}$ denotes the mean molal activity coefficient for pure $\mathrm{NaCl}$ solution. $E_{0}$ and $k$ can be obtained from this equation by using a least square fitting procedure. For the $\mathrm{HEPES}-\mathrm{NaCl}$ and MOPSO-NaCl two-component systems, if the concentrations of $\mathrm{NaCl}$ in cells (II) and (III) are the same as that in the pure $\mathrm{NaCl}$ solutions, then we can combine Eqs. (1) and (2) to obtain

$$
\log \left(\gamma_{1} / \gamma_{1}^{0}\right)=\left(E_{\mathrm{p}}-E\right) / 2 k
$$

where $E_{\mathrm{p}}$ is the emf for pure $\mathrm{NaCl}$ solution from cell (I). All the emfs and $\log \left(\gamma_{1} / \gamma_{1}{ }^{\circ}\right)$ values are listed in Tables 1 and 2 together with $k$ values at four temperatures. All the molalities in Tables 1 and 2 are accurate to better than $0.1 \%$.

\subsection{Influence of HEPES and MOPSO on the Activity Coefficient of $\mathrm{NaCl}$}

The values of $\log \left(\gamma_{1} / \gamma_{1}^{\circ}\right)$ at $25^{\circ} \mathrm{C}$ from Tables 1 and 2 were plotted against the molality of HEPES and MOPSO in Figs. 1 and 2, respectively. The trend of the behavior of $\left.\log \left(\gamma_{1} / \gamma_{1}\right)^{\circ}\right)$ was similar to that for other amino acids [1]. HEPES and MOPSO diminished the activity coefficients of 
Table 1. The emfs of the cell: $\mathrm{NaISE} / \mathrm{NaCl}\left(m_{1}\right), \operatorname{HEPES}\left(m_{2}\right)$, NaHEPESate $\left(m_{3}\right) / \mathrm{AgCl}, \mathrm{Ag}$ and the $\log \left(\gamma_{1} / \gamma_{1}{ }^{\circ}\right)$ values

\begin{tabular}{|c|c|c|c|c|c|c|c|c|c|c|}
\hline$m_{1}$ & ${ }^{t{ }^{\circ} \mathrm{C}}$ & $m_{3}$ & $E, \mathrm{mV}$ & $-\log \left(\gamma_{1} / \gamma_{1}{ }^{\circ}\right)$ & $E$ & $\begin{array}{l}15 \\
-\log \left(\gamma_{1} / \gamma_{1}{ }^{\circ}\right)\end{array}$ & $E$ & $\begin{array}{l}25 \\
-\log \left(\gamma_{1} / \gamma_{1}{ }^{\circ}\right)\end{array}$ & $E$ & $\begin{array}{c}37 \\
-\log \left(\gamma_{1} / \gamma_{1}^{\circ}\right)\end{array}$ \\
\hline 0.01 & 0 & 0 & 58.3 & & 68.6 & & 76.3 & & 87.2 & \\
\hline 0.02 & 0 & 0 & 27.7 & & 36.3 & & 42.8 & & 52.1 & \\
\hline 0.02 & 0.05 & 0 & & & & & 43.5 & 0.0060 & & \\
\hline 0.02 & 0.08 & 0 & & & & & 44.1 & 0.0111 & & \\
\hline 0.02 & 0.1 & 0 & & & & & 44.5 & 0.0145 & & \\
\hline 0.02 & 0.12 & 0 & & & & & 44.9 & 0.0179 & & \\
\hline 0.05 & 0 & 0 & -13.1 & & -6.1 & & -1.0 & & 6.9 & \\
\hline 0.05 & 0.05 & 0 & & & & & -0.4 & 0.0051 & & \\
\hline 0.05 & 0.08 & 0 & & & & & 0.2 & 0.0102 & & \\
\hline 0.05 & 0.1 & 0 & & & & & 0.5 & 0.0128 & & \\
\hline 0.05 & 0.12 & 0 & & & & & 1.0 & 0.0171 & & \\
\hline 0.08 & 0 & 0 & -34.1 & & -27.6 & & -22.7 & & -16.3 & \\
\hline 0.08 & 0.05 & 0 & -33.5 & 0.0055 & -27.0 & 0.0053 & -22.1 & 0.0051 & -15.7 & 0.0049 \\
\hline 0.08 & 0.08 & 0 & -33.0 & 0.0101 & -26.5 & 0.0097 & -21.6 & 0.0094 & -15.2 & 0.0090 \\
\hline 0.08 & 0.1 & 0 & -32.6 & 0.0138 & -26.1 & 0.0132 & -21.3 & 0.0120 & -14.9 & 0.0115 \\
\hline 0.08 & 0.12 & 0 & -32.2 & 0.0175 & -25.7 & 0.0167 & -20.9 & 0.0154 & -14.6 & 0.0139 \\
\hline 0.1 & 0 & 0 & -42.6 & & -37.4 & & -33.3 & & -27.3 & \\
\hline 0.1 & 0.05 & 0 & & & & & -32.8 & 0.0043 & & \\
\hline 0.1 & 0.08 & 0 & & & & & -32.3 & 0.0085 & & \\
\hline 0.1 & 0.1 & 0 & & & & & -32.0 & 0.0111 & & \\
\hline 0.1 & 0.12 & 0 & & & & & -31.7 & 0.0137 & & \\
\hline 0.08 & 0.08 & 0.08 & -47.1 & & -41.1 & & -36.3 & & -30.1 & \\
\hline \multicolumn{3}{|c|}{$k(\mathrm{mV})$} & 54.2 & & 56.7 & & 58.5 & & 61.2 & \\
\hline
\end{tabular}

Table 2. The emfs of the cell: $\mathrm{NaISE} / \mathrm{NaCl}\left(m_{1}\right), \operatorname{MOPSO}\left(m_{2}\right), \operatorname{NaMOPSOate}\left(m_{3}\right) / \mathrm{AgCl}, \mathrm{Ag}$ and the $\log \left(\gamma_{1} / \gamma_{1}{ }^{\circ}\right)$ values

\begin{tabular}{|c|c|c|c|c|c|c|c|c|c|c|}
\hline$m_{1}$ & $\begin{array}{r}t^{\circ} \mathrm{C} \\
\mathrm{m}_{2} \\
\end{array}$ & $m_{3}$ & $E, \mathrm{mV}$ & $\begin{array}{l}5 \\
-\log \left(\gamma_{1} / \gamma_{1}{ }^{\circ}\right) \\
\end{array}$ & $E$ & $\begin{array}{l}15 \\
-\log \left(\gamma_{1} / \gamma_{1}{ }^{\circ}\right)\end{array}$ & $E$ & $\begin{array}{l}25 \\
-\log \left(\gamma_{1} / \gamma_{1}^{\circ}\right)\end{array}$ & $E$ & $\begin{aligned} & 37 \\
&- \log \left(\gamma_{1} / \gamma_{1}{ }^{\circ}\right) \\
&\end{aligned}$ \\
\hline 0.01 & 0 & 0 & -19.8 & & -10.0 & & -2.5 & & 10.5 & \\
\hline 0.02 & 0 & 0 & -51.2 & & -43.2 & & -36.0 & & -24.9 & \\
\hline 0.02 & 0.05 & 0 & & & & & -35.6 & 0.0034 & & \\
\hline 0.02 & 0.08 & 0 & & & & & -35.2 & 0.0068 & & \\
\hline 0.02 & 0.1 & 0 & & & & & -34.9 & 0.0094 & & \\
\hline 0.02 & 0.12 & 0 & & & & & -34.5 & 0.0128 & & \\
\hline 0.02 & 0.15 & 0 & & & & & -34.0 & 0.0171 & & \\
\hline 0.05 & 0 & 0 & -91.8 & & -85.4 & & -79.5 & & -70.6 & \\
\hline 0.05 & 0.05 & 0 & & & & & -79.1 & 0.0034 & & \\
\hline 0.05 & 0.08 & 0 & & & & & -78.7 & 0.0068 & & \\
\hline 0.05 & 0.1 & 0 & & & & & -78.4 & 0.0094 & & \\
\hline 0.05 & 0.12 & 0 & & & & & -78.0 & 0.0128 & & \\
\hline 0.05 & 0.15 & 0 & & & & & -77.5 & 0.0171 & & \\
\hline 0.08 & 0 & 0 & -112.7 & & -106.9 & & -101.8 & & -93.7 & \\
\hline 0.08 & 0.05 & 0 & -112.2 & 0.0046 & -106.5 & 0.0035 & -101.4 & 0.0034 & -93.3 & 0.0032 \\
\hline 0.08 & 0.08 & 0 & -111.7 & 0.0092 & -106.0 & 0.0080 & -101.0 & 0.0068 & -93.0 & 0.0057 \\
\hline 0.08 & 0.1 & 0 & -111.4 & 0.0120 & -105.7 & 0.0106 & -100.7 & 0.0094 & -92.7 & 0.0081 \\
\hline 0.08 & 0.12 & 0 & -111.1 & 0.0147 & -105.4 & 0.0133 & -100.4 & 0.0119 & -92.4 & 0.0105 \\
\hline 0.08 & 0.15 & 0 & -110.6 & 0.0193 & -104.9 & 0.0177 & -99.9 & 0.0162 & -91.9 & 0.0146 \\
\hline 0.1 & 0 & 0 & -121.3 & & -116.8 & & -112.2 & & -105.2 & \\
\hline 0.1 & 0.05 & 0 & & & & & -111.8 & 0.0034 & & \\
\hline 0.1 & 0.08 & 0 & & & & & -111.5 & 0.0060 & & \\
\hline 0.1 & 0.1 & 0 & & & & & -111.2 & 0.0085 & & \\
\hline 0.1 & 0.12 & 0 & & & & & -110.9 & 0.0111 & & \\
\hline 0.1 & 0.15 & 0 & & & & & -110.4 & 0.0153 & & \\
\hline 0.05 & 0.05 & 0.05 & -112.8 & & -104.0 & & -96.0 & & -83.7 & \\
\hline 0.08 & 0.08 & 0.08 & -132.2 & & -124.7 & & -117.2 & & -106.3 & \\
\hline \multicolumn{3}{|c|}{$k(\mathrm{mV})$} & 54.4 & & 57.0 & & 58.6 & & 61.7 & \\
\hline
\end{tabular}


$\mathrm{NaCl}$; the effect of HEPES was more pronounced than that of MOPSO. An increase in the $\mathrm{NaCl}$ concentration decreased the effect of amino acids. The values of $\log \left(\gamma_{1} / \gamma_{1}{ }^{\circ}\right)$ at $25^{\circ} \mathrm{C}$ can be represented by the following equations:

HEPES- $\mathrm{NaCl}$ solution,

$$
\begin{aligned}
& -\log \left(\gamma_{1} / \gamma_{1}{ }^{0}\right)=\left(0.11-0.42 m_{1}\right) m_{2} \\
& +\left(0.45-0.44 m_{1}\right) m_{2}^{2}
\end{aligned}
$$

MOPSO- $\mathrm{NaCl}$ solution,

$$
\begin{aligned}
& -\log \left(\gamma_{1} / \gamma_{1}{ }^{\circ}\right)=\left(0.05+0.04 m_{1}\right) m_{2} \\
& +\left(0.51-1.4 m_{1}\right) m_{2}^{2} .
\end{aligned}
$$

The temperature effect is shown in Figs. 3 and 4 at $m_{2}=0.08$. In our previous paper [2], we used the following equation for HEPES-NaCl solutions at $m_{\mathrm{NaCl}}=0.08$ and assumed that it was temperatureindependent:

$$
-\log \left(\gamma_{1} / \gamma_{1}^{\circ}\right)=0.125 m_{\text {HEPES }}
$$

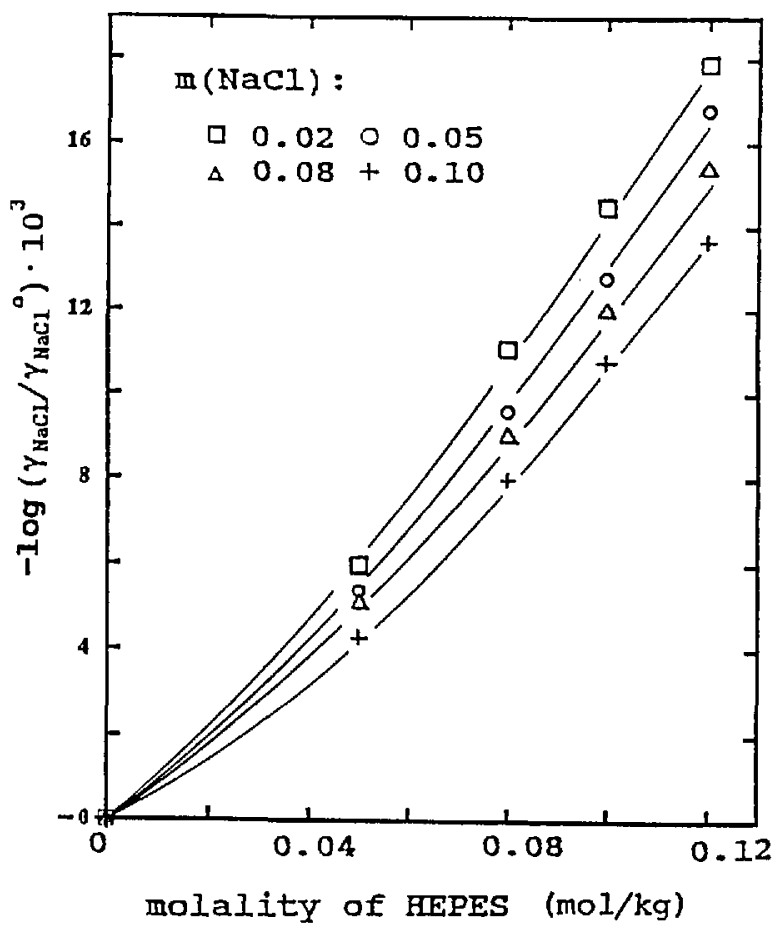

Figure 1. Influence of HEPES on activity coefficient of $\mathrm{NaCl}$ at $25^{\circ} \mathrm{C}$.

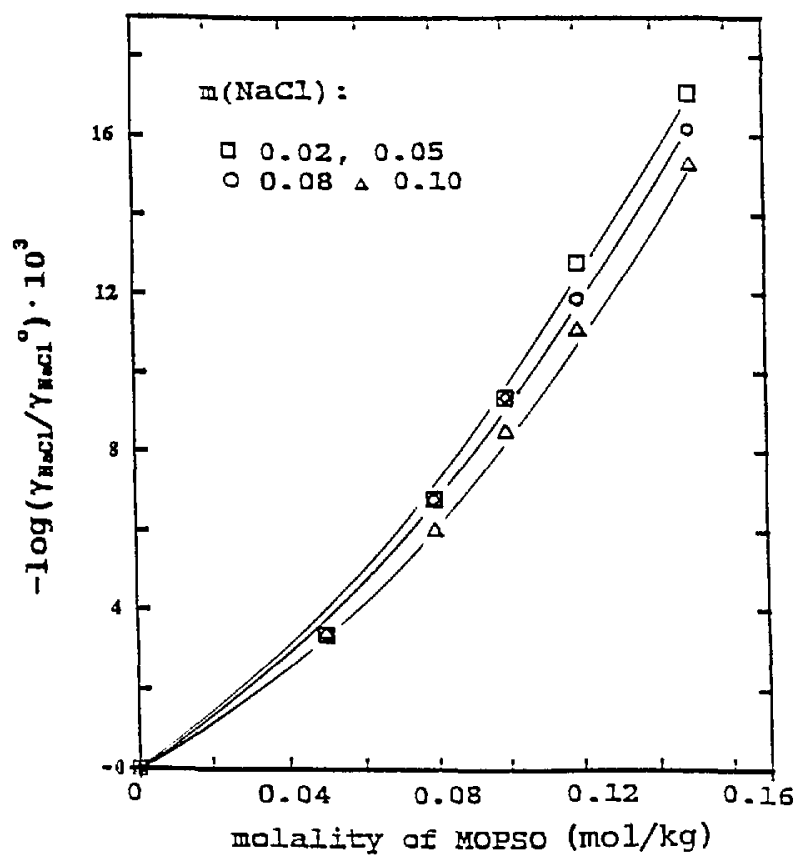

Figure 2. Influence of MOPSO on activity coefficient of $\mathrm{NaCl}$ at $25^{\circ} \mathrm{C}$.

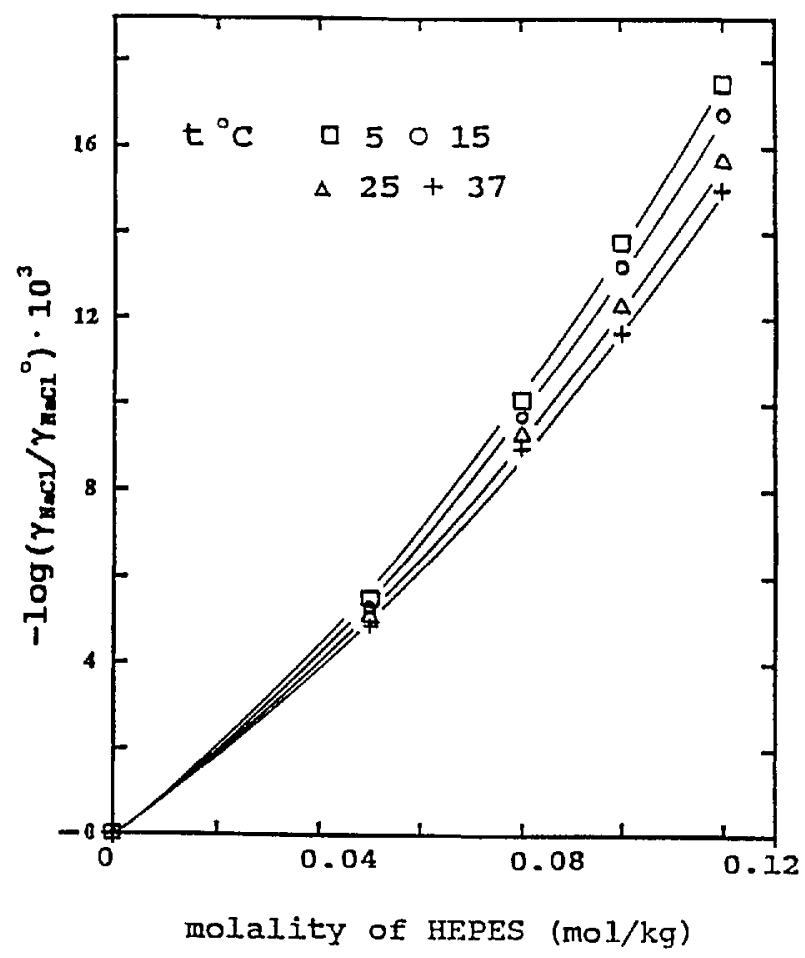

Figure 3. Influence of HEPES on activity coefficient of $\mathrm{NaCl}$ at different temperatures, $m(\mathrm{NaCl})=0.08$. 




Figure 4. Influence of MOPSO on activity coefficient of $\mathrm{NaCl}$ at different temperatures, $m(\mathrm{NaCl})=0.08$.

The $\log \left(\gamma_{1} / \gamma_{1}{ }^{\circ}\right)$ values calculated from Eq. (6) and observed experimentally (cf. Table 1 ) are listed in Table 3. The difference is within the experimental uncertainty.

Table 3. Comparison of $\log \left(\gamma_{1} / \gamma_{1}^{\circ}\right)$ at $m_{2}=0.08$

\begin{tabular}{rcc}
\hline \hline & \multicolumn{2}{c}{$-\log \left(\gamma_{1} / \gamma_{1}{ }^{\circ}\right)$} \\
$t^{\circ} \mathrm{C}$ & Observed & $\begin{array}{c}\text { Calculated } \\
\text { from Eq. (6) }\end{array}$ \\
\hline 5 & 0.0101 & 0.010 \\
15 & 0.0097 & 0.010 \\
25 & 0.0094 & 0.010 \\
37 & 0.0090 & 0.010 \\
\hline
\end{tabular}

\subsection{The Activity Coefficient of $\mathrm{NaCl}$ in MOPSO- NaMOPSOate-NaCl Buffer Solutions}

Data for the activity coefficients of $\mathrm{NaCl}$ are needed in the determination of the $\mathrm{pH}$ of threecomponent MOPSO-NaMOPSOate- $\mathrm{NaCl}$ buffer solutions. In this work, $\log \gamma_{\mathrm{NaC}}$ in 0.05 and $0.08 \mathrm{~m}$ equimolal MOPSO-NaMOPSOate- $\mathrm{NaCl}$ solutions was directly determined by using cell (III). For this cell,

$$
\log \gamma_{1}=1 / 2\left[\left(E_{0}-E\right) / k-\log \left(m_{1}+m_{3}\right) m_{1}\right]
$$

where $E_{0}$ and $k$ were obtained from the measurements of cell (I). The results, listed in Table 4, are used for the determination of the $\mathrm{pH}$ values in these buffer solutions.

Table 4. Determination of $\gamma_{\mathrm{NaCl}}$ in MOPSO-NaMOPSOate$\mathrm{NaCl}$ solutions

\begin{tabular}{rcc}
\hline \hline & \multicolumn{2}{c}{$-\log \gamma_{\mathrm{NaCl}}$} \\
$t^{\circ} \mathrm{C}$ & $0.05 m$ (equimolal) & $0.08 m$ (equimolal) \\
\hline 5 & 0.039 & 0.064 \\
15 & 0.070 & 0.091 \\
25 & 0.096 & 0.119 \\
37 & 0.132 & 0.153 \\
\hline
\end{tabular}

\subsection{Activity Coefficients of HEPES and MOPSO}

According to the Gibbs-Duhem equation, the activity coefficient of an amino acid in an amino acid- $\mathrm{NaCl}$ two-component solution can be calculated from the activity coefficient of $\mathrm{NaCl}$ in the same solution [1]:

$$
\left.\log \left(\gamma_{2} / \gamma_{2}{ }^{\circ}\right)=2 \int_{0}^{m_{1}} \partial \log \gamma_{1} / \partial m_{2}\right) \partial m_{1}
$$

where $\gamma_{2}$ is the activity coefficient of the amino acid in the mixed solution and $\gamma_{2}{ }^{\circ}$ is that for an isomolal solution without $\mathrm{NaCl}, \gamma_{1}$ is the activity coefficient of $\mathrm{NaCl}$ in this mixed solution. By substituting Eqs. (4) and (5) into Eq. (8), $\log \left(\gamma_{2} / \gamma_{2}{ }^{\circ}\right)$ can be evaluated. $\log \gamma_{2}^{\circ}$ for HEPES at $25^{\circ} \mathrm{C}$ was calculated from emf measurements of the following cell,

$$
\begin{gathered}
\mathrm{H}_{2}(\mathrm{~g}, 1 \mathrm{~atm}) / \mathrm{HEPES}, \mathrm{NaHEPESate}, \mathrm{NaCl} / \\
\mathrm{AgCl}, \mathrm{Ag}(\mathrm{s})
\end{gathered}
$$

as described in our previous paper [2], in which $\gamma_{Z \pm}$ represented $\gamma_{\text {HEPES }}$ :

$$
-\log \gamma_{\mathrm{HEPES}}{ }^{\circ}=0.20 m_{\mathrm{HEPES}} .
$$

Analogous measurements were carried out for MOPSO at $25^{\circ} \mathrm{C}$ [7] and the following result was obtained:

$$
-\log \gamma_{\text {MOPSO}}{ }^{\circ}=0.10 m_{\text {MOPSO }} .
$$

Thus, from Eqs. (8), (9) and (10), the activity coefficients of HEPES and MOPSO at $25^{\circ} \mathrm{C}$ are expressed as follows:

$$
\begin{gathered}
\log \gamma_{\mathrm{HEPES}}=\left(-0.22 m_{\mathrm{NaCI}}+0.42 m_{\mathrm{NaCl}}{ }^{2}\right) \\
-\left(0.20+1.8 m_{\mathrm{NaC}}-0.88 m_{\mathrm{NaCl}}^{2}\right) m_{\mathrm{HEPES}}
\end{gathered}
$$




$$
\begin{gathered}
\log \gamma_{\mathrm{MOPSO}}=\left(-0.10 m_{\mathrm{NaCl}}-0.04 m_{\mathrm{NaCl}}{ }^{2}\right) \\
-\left(0.10+2.0 m_{\mathrm{NaCl}}-2.8 m_{\mathrm{NaCl}}\right) m_{\mathrm{MOPSO}}
\end{gathered}
$$

Taking the first-order terms as an approximation, the following simpler forms result. For comparison, the analogous expression for glycine [1] is also shown:

$$
\begin{aligned}
& \log \gamma_{\mathrm{HEPES}}=-0.20 m_{\mathrm{HEPES}}-0.22 m_{\mathrm{NaCl}} \\
& \log \gamma_{\mathrm{MOPSO}}=-0.10 m_{\mathrm{MOPS}}-0.10 m_{\mathrm{NaCl}} \\
& \log \gamma_{\text {Glycine }}=-0.10 m_{\text {Glycine }}-0.28 m_{\mathrm{NaCl}} .
\end{aligned}
$$

\section{Discussion}

All the parameters used for Eqs. (4), (5), (13), and (14) are empirical. They are derived from the least square fitting of the experimental data and are only valid within the range of the concentrations in this work. According to Cohn and Edsall [1], at low $\mathrm{NaCl}$ concentrations, most amino acids diminish the activity coefficients of $\mathrm{NaCl}$, and $\mathrm{NaCl}$ in turn diminishes the activity coefficients of amino acids. The present work demonstrates a similar phenomenon in the $\mathrm{NaCl}-\mathrm{HEPES}$ and $\mathrm{NaCl}-$ MOPSO systems.

Because of the relatively high input impedance of the NaISE, a pH meter was used to measure the emfs of cells (I), (II), and (III). The resolution of this $\mathrm{pH}$ meter was $0.1 \mathrm{mV}$. This corresponds to an uncertainty of 0.0017 in $\log \left(\gamma_{1} / \gamma_{1}{ }^{\circ}\right)$. Each emf value reported in Tables 1 and 2 represents the mean of two separate measurements. The differences between each pair of emf values never exceeded $0.1 \mathrm{mV}$. Therefore, the overall uncertainty of $\log \left(\gamma_{1} / \gamma_{1}{ }^{\circ}\right)$ is estimated to be $0.0017 / \sqrt{2}=0.0012$. The trend of the influence of the amino acid on the activity coefficients of $\mathrm{NaCl}$, as indicated by $\log \left(\gamma_{1} / \gamma_{1}{ }^{\circ}\right)$ and shown in Figs. 1-4, is more evident at higher concentrations of the two amino acids. As the concentration becomes lower, the influence diminishes. In the lowest concentration region, the differences in the $\lg \left(\gamma_{1} / \gamma_{1}^{\circ}\right)$ values at different $\mathrm{NaCl}$ concentrations or temperatures are within the limit of uncertainty and in some cases the $\log \left(\gamma_{1} / \gamma_{1}{ }^{\circ}\right)$ values practically overlap. The curves drawn in this region are merely to show the trend of the influence.

\section{Acknowledgment}

The authors are grateful to Prof. W. Simon for kindly providing the PVC membrane NaISE.

\section{References}

[1] E. J. Cohn and J. T. Edsall, Proteins, Amino Acids and Peptides, Chapt. 11, Hafner Publishing Co., New York (1965).

[2] D. Feng, W. F. Koch, and Y. C. Wu, Anal. Chem. 61, 1400 (1989)

[3] N. R. Joseph, Biol. Chem. 111, 489 (1935).

[4] T. Maruizumi, D. Wegmann, G. Suter, D. Ammann, and W. Simon, Mikrochim. Acta I, 331 (1986).

[5] W. J. Hamer and Y. C. Wu, J. Phys. Chem. Ref. Data 1, 1047 (1972), for $25^{\circ}$ C; R. A. Robinson and R. H. Stokes, Electrolyte Solutions, Butterworths Scientific Publications, London (1959) for other temperatures.

[6] Fisher Scientific, Manual of sodium ion-selective electrodes, part No. 69491 (1987].

[7] To be published.

About the authors: Yung $C$. Wu and William F. Koch are chemists with the Inorganic Analytical Research Division, National Institute of Standards and Technology. Daming Feng is guest scientist from Guangzhou Research Institute of Non-ferrous Metals, China. 